University of Michigan Law School University of Michigan Law School Scholarship Repository

1994

\title{
Conditional Probative Value: Neoclassicism without Myth
}

Richard D. Friedman

University of Michigan Law School, rdfrdman@umich.edu

Available at: https://repository.law.umich.edu/articles/170

Follow this and additional works at: https://repository.law.umich.edu/articles

Part of the Evidence Commons

\section{Recommended Citation}

Friedman, Richard D. "Conditional Probative Value: Neoclassicism without Myth." Mich. L. Rev. 93, no. 3 (1994): 439-77.

This Article is brought to you for free and open access by the Faculty Scholarship at University of Michigan Law School Scholarship Repository. It has been accepted for inclusion in Articles by an authorized administrator of University of Michigan Law School Scholarship Repository. For more information, please contact mlaw.repository@umich.edu. 


\title{
CONDITIONAL PROBATIVE VALUE: NEOCLASSICISM WITHOUT MYTH
}

\author{
Richard D. Friedman*
}

\section{INTRODUCTION}

The concept of conditional relevance is an essential aspect of the classical model of evidentiary law. Some of the great scholars of evidence have endorsed and shaped it. ${ }^{1}$ Under Federal Rule of Evidence 104(b) it plays a crucial role in the division of responsibility between judge and jury, ${ }^{2}$ as well as in the application of the personal knowledge 3 and authentication ${ }^{4}$ requirements. And the Supreme Court has applied it with great force. 5

In recent years, though, the concept has come under attack from several notable scholars. The late Vaughn Ball led the assault, calling the concept a "myth."6 Peter Tillers, finding Ball's analysis to have some merit ${ }^{7}$ but not to be entirely satisfying, concludes that "[a]s a device for the regulation of fact-finding chores by the jury," the doctrine of conditional relevance "seems particularly invidious since it is so susceptible of witting or unwitting manipulation by judges who are distrustful of juries." 8 Dale Nance has found Ball's criticisms convincing as applied to the hypotheticals and cases by which conditional relevance is usually explained; what "residual

* Professor of Law, University of Michigan. B.A. 1973, J.D. 1976, Harvard; D.Phil. 1979, Oxford. - Ed. Many thanks for helpful comments, suggestions, and criticisms to Ron Allen, Rick Lempert, and Peter Tillers, and especially to Dale Nance for the extraordinary energy he put into making extremely useful comments and corrections.

1. See, e.g., 3 JoHN HENRY WIGMORE, EVIDENCE $§ 1871$ (1st ed. 1904); 1 JACK B. WeINSTEIN \& MARGARET A. Berger, WeINSTEIN's EvidENCE II 104(01) (1994); John MacArthur Maguire \& Charles S.S. Epstein, Preliminary Questions of Fact in Determining the Admissibility of Evidence, 40 HARv. L. Rev. 392 (1927). An article by Edmund Morgan is widely accorded great weight in giving the concept of conditional relevance its present form. See Edmund M. Morgan, Functions of Judge and Jury in the Determination of Preliminary Questions of Fact, 43 HARV. L. REv. 165 (1929).

2. See FED. R. EvID. 104(b).

3. Compare FED. R. EvID. 104(b) with FED. R. Evid. 602; see infra section V.C. V.D.

4. Compare FED. R. Evid. 104(b) with FED. R. Evid. 901(a); see infra sections II.D, IV.C,

5. See Huddleston v. United States, 485 U.S. 681 (1988).

6. See Vaughn C. Ball, The Myth of Conditional Relevancy, 14 GA. L. REv. 435 (1980).

7. See 1 John Henry Wigmore, Evidence $§ 14.1$, at 718, 725 (Tillers rev. ed. 1983) [hereinafter WIGMORE (Tillers ed.)].

8. Id. $\S 14.1$, at $730-31$. 
force" he perceives in the concept of conditional relevance should, he believes, be accounted for not on traditional grounds but as an application of the "best evidence principle."9 Most recently, Ronald Allen, like Ball, has spoken of conditional relevance as a "myth";10 he contends that "there is no independent scope for the concept of conditional relevanc[e]."11

In this article, I contend that, although the classical concept of conditional relevance is flawed in some respects, there is more to the concept than one might infer from the work of these writers.

I certainly do agree with them that the concept as traditionally expressed can be misleading. In two senses, it is too formalistic. First, as I show in Part I, it is binary when it should operate in terms of degree; thus we might speak more precisely, when precision is really necessary, in terms of conditional probative value. Second, as I argue in Part II, the traditional doctrine intrudes too much on the jury's function. ${ }^{12}$ It attempts to divide into discrete parts a factfinding task that is better left integral. It does this by supposing that the jury will determine the truth, not only of the ultimate factual propositions made material by the governing substantive law, but also of preliminary, or predicate, propositions on which the relevance of proffered evidence may be conditional. I will argue that the very notion of a predicate proposition, which is central to the traditional concept of conditional relevance, is an unwarranted formalization unless treated merely as a useful shorthand.

In Part III, I define conditional probative value, a concept that shares the basic theoretical foundation of conditional relevance while avoiding its formalism. This Part shows that a determination of the conditional probative value of a given piece of evidence is much like the ordinary determination of probative value - except that the determination must be made twice, once with a prescribed evidentiary condition satisfied and once without. The essence of the concept of conditional probative value lies in comparison of these two determinations: proffered evidence has probative value

9. See Dale A. Nance, Conditional Relevance Reinterpreted, 70 B.U. L. REv. 447, 448 (1990). I join Nance, against the Federal Rules and most evidence scholars, in speaking of relevance rather than relevancy. The extra syllable seems superfluous and somewhat anachronistic, as in independency; moreover, standard dictionaries seem to prefer relevance. By the same ratio decidendi, I prefer competence to competency.

10. See Ronald J. Allen, The Myth of Conditional Relevancy, 25 Loy. L.A. L. REv. 871 (1992).

11. Id. at 880 .

12. In many places throughout this article, fact finder could be substituted for jury, and in some circumstances I will refer in general terms to a fact finder. But the issues are more consistently salient - clearer and more consequential - when the case is tried to a jury. 
subject to a given condition if its probative value is greater when that condition is satisfied than when the condition is not satisfied.

Understood in this manner, the concept is useful in various contexts, as I contend in Part IV. Thus, I believe the expression of the concept in evidentiary rules should not be discarded but rather refreshed. In Part V, I propose a redraft of Rule 104(b) and of associated rules, including those dealing with the personal knowledge and authentication requirements. The concept expressed by these proposals resembles, but lacks the rigid lines of, the traditional concept. Thus, I call it neoclassical. And it is no myth.

\section{Conditional Relevance and Conditional Probative VALUE}

Rule 104(b) expresses the classical concept of conditional relevance:

Relevancy conditioned on fact. When the relevancy of evidence depends upon the fulfillment of a condition of fact, the court shall admit it upon, or subject to, the introduction of evidence sufficient to support a finding of the fulfillment of the condition. ${ }^{13}$

To see how the classical concept operates, consider the following hypothetical:

Blanca's hypothetical: Blanca is being tried for improper disposal of refuse. Under the governing law, an element of the crime charged is the factual proposition that at the time of her alleged conduct - mixing newspapers with trash - she knew that it was prohibited. To help prove Blanca's knowledge, Proffer, the prosecutor, offers evidence that a document created before the time of Blanca's conduct stated the prohibition.

Analysis of this hypothetical will be assisted by defining the following propositions:

Knew is the proposition, made material by the governing law, that at the time of her conduct Blanca knew that it was illegal.

Statement is the proposition that a document created before the time of Blanca's alleged conduct stated the prohibition.

Learn is the proposition that Blanca read or otherwise learned of the contents of the document by the time of her alleged conduct.

Proffer's evidence of Statement would clearly be relevant to Knew if Learn were known to be true. ${ }^{14}$ If Learn is known not to

13. FED. R. Evid. 104(b).

14. It might seem that this is something of an understatement, because if Statement and Learn are both true then Knew must be true. But in fact Statement-and-Learn does not necessarily imply Knew: it may be, for example, that Blanca thought the statement was a joke or inaccurate, or that she did not fully understand it, or that by the time of her conduct 
be true, however, Statement does not appear relevant with respect to Knew. ${ }^{15}$ Accordingly, under the classical concept, Statement is said to be relevant conditionally upon sufficient proof of the truth of the predicate Learn.

Some critics have pointed out that one problem with this classical concept of conditional relevance is that it does not square well with the broad, basic concept of relevance. ${ }^{16}$ Generally speaking, they say, evidence that is conditionally relevant under Rule 104(b) must, even without evidence of the predicate, satisfy the ordinary standard of relevance, which is expressed in Federal Rule of Evidence 401:

"Relevant evidence" means evidence having any tendency to make the existence of any fact that is of consequence to the determination of the action more probable or less probable than it would be without the evidence. ${ }^{17}$

Given sufficient proof of Learn, evidence of Statement is clearly relevant to Knew, a fact "that is of consequence to the determination of the action," because Knew is more probable given both Learn and Statement than it would be given Learn but without any proof of Statement. ${ }^{18}$ But even if there is no proof of Learn, Statement is still relevant with respect to Knew, so long as Learn is possible: evidence leading a jury to believe that Statement is true will probably lead the jury to believe that the conjunction of the two propositions, Statement-and-Learn, and therefore also Knew, is more likely true than it would be in the absence of the evidence. Proof that one hurdle - here, Statement - has been jumped makes more likely the proposition that both this hurdle and one other have been jumped. ${ }^{19}$

she had forgotten it. Moreover, only in rare circumstances, and arguably never, would Proffer's evidence of Statement prove Statement true conclusively.

15. Some qualification of this statement may be appropriate. See infra section II.E (discussing the uncertain nature of the predicate proposition).

16. See Wigmore (Tillers ed.), supra note $7, \S 14.1$, at 720 ("[C]onditionally relevant evidence (taken separately) may have little probative value if the probability of the condition is low but ... such conditionally relevant evidence may still have some probative value."); Allen, supra note 10, at 883-84 (arguing that FED. R. EviD. 104(b) should be amended to implement the definition of relevance in FED. R. Evid. 401 by recognizing that "[i]f there is any probability that a reasonable person could be rationally influenced by evidence, the evidence is relevant"); Ball, supra note 6, at $446-49$ (emphasizing that relevance does not depend upon the extent to which evidence alters the probability of a material fact, if it alters that probability at all, and showing that evidence regarded as conditionally relevant under the classical model may be relevant even if the conditioning fact is probably false).

17. FED. R. Evid. 401 (emphasis added).

18. Even if Learn and Statement are both true, Knew is not certain. See supra note 14.

19. See Ball, supra note 6 , at $445-54$ (arguing that conditionally relevant evidence is relevant per se unless the probability of the conditional event is zero). The analysis here is, I believe, in accord with that in Allen, supra note 10, at 873, discussing a hypothetical case in 
What can be said of this case can be said of most others: If an item of evidence is relevant assuming the truth of a particular factual condition, then so long as that factual condition is possible the item of evidence will be relevant, in the broad sense that it alters the probability of a material fact, even if the factual condition is unproven. But the significance of this proposition is limited in at least two important respects.

First, there are in fact cases in which an item of evidence has substantial probative value given proof of another proposition but is irrelevant absent such evidence. Consider an assault case in which identity is at issue. Suppose that an eyewitness has identified the accused as the assailant and that the accused has denied that he was even present at the scene. In this context, evidence of proposition $A$, that the accused has blood type $\mathrm{A}$, does not appear to have any probative value at all; so far as I am aware, there are no studies suggesting that a given person is more or less likely to commit crimes if he has blood type $A$ than if he has other types. But if the defense offers proof of proposition $B$, that the assailant, whoever it was, had blood type $\mathrm{B}$, then the evidence of proposition $A$ gains great - indeed, nearly dispositive - probative value. Various forms of identification evidence - identifying a person or thing as the one that played a given role in the case by showing that each shares a given characteristic that has no relevance to the case but for that commonality - fit this mold of what might be called absolute conditional relevance. ${ }^{20}$

which the material issues are, first, whether there was offer and acceptance and, second, whether the agent who assertedly accepted was authorized to do so:

Assume that the probability of authority is not 0.0 . In that case, any evidence that affects the probability of offer and acceptance obviously may affect the outcome of the case. By making the probability of offer and acceptance higher or lower, the probability of which one of the parties will ultimately prevail is changed, which obviously means the evidence is relevant.

Id.; see also WrgmoRe (Tillers ed.), supra note 7, § 14.1, at $718 \mathrm{n} .18$ ("The fallacy [of Mor' gan's analysis] lies in misinterpreting the implications of the proposition that $A$ is not relevant if it is known that $B$ does not exist. This proposition does not establish that $A$ is not relevant if B's existence is only probable, regardless of how low that probability might be.").

20. In a long footnote, Ball addresses a similar hypothetical involving evidence of the blood type of a suspect and of the perpetrator. See Ball, supra note $6 ;$ at $466.69,469$ n.38. Ball contends that even here the concept of conditional relevance has no role to play. He argues that each individual piece of evidence is relevant in itself because, while it leaves unchanged the probability of the ultimate fact to be determined - whether the accused was the perpetrator - it increases the probability of at least one version of how that fact could be true and decreases the probability of at least one other version. Id. at $469 \mathrm{n.38}$. Thus, to use an example similar to Ball's, indisputable proof of evidence $B$ - that the perpetrator had type $B$ blood - would eliminate the possibility of the conjoint proposition that the accused has type $\mathrm{A}$ blood and committed the crime, and similar possibilities involving types $\mathrm{O}$ and $\mathrm{AB}$ blood, but would increase the probability of the conjoint proposition that the accused has 
Second, and more important, that a proffered piece of evidence is relevant to a material factual proposition, even absent proof of another proposition, does not in itself generally have much signifcance. For example, to say that evidence of Statement is relevant in proving Knew, even absent proof of Learn, does not take us very far. It says that Knew is more likely given the evidence, but it does not tell us how much more likely. This is crucial. Often an item of evidence is technically relevant, in that it raises or lowers the probability of a material fact, but the extent of that impact - the probative value of the evidence - is too minuscule to warrant admissibility.21

If, for example, the document in question is a private letter between two people having no apparent connection to Blanca, a reasonable jury would have to believe, absent proof of Learn, that the probability of Learn is rather low. Thus, evidence of Statement probably would not, absent proof of Learn, raise the probability of Knew very much at all. In such a case, we might say that evidence of Statement has significant conditional probative value, dependent

type B blood and committed the crime. The overall probability that the accused committed the crime would not, of course, be altered by evidence $B$ alone.

It seems to me that it stretches the concept of relevance out of shape to contend, as Ball does, that evidence $B$ is in itself relevant. The proposition of consequence to the determination of the action is that the accused was the perpetrator, and evidence $B$ does not in itself alter that probability: if no evidence of the accused's blood type is introduced, admitting evidence $B$ would be a waste of time. That evidence $B$ increases the probability of the conjoint proposition that the accused has type B blood and committed the crime, while diminishing other possibilities involving the accused's crime, is significant only if evidence of the accused's blood type is introduced. The if, of course, represents the condition on the relevance of evidence $B$. In short, Ball has effectively stretched the definition of relevance to a situation in which it does not belong and used this extended definition to argue that the concept of conditional relevance has no useful purpose - even though conditional relevance describes the situation well.

Indeed, under Ball's definition all evidence would be relevant to any material proposition $X$ : proof of evidentiary proposition $A$ makes more likely the conjoint proposition $A$ and $X$, even while it disproves the conjoint proposition Not-A and $X$. But if proof of $A$ does not alter the probability of $X$ itself, no matter what the other evidence may be, then it becomes meaningless to call the evidence relevant. If, on the other hand, evidence of $A$ alters the probability of $X$ given evidence of proposition $B$, but not otherwise, then describing the evidence of $A$ as conditionally relevant to $X$ on proof of $B$ seems entirely appropriate.

21. Suppose, for example, that in a trial for a murder without an eyewitness - other than the murderer - the prosecutor wishes to prove that a particular member of the community, with no other apparent connection to the case, was out of town on the day of the murder. This evidence does increase the probability that the accused committed the murder - after all, it reduces the universe of alternative suspects by one - but it clearly does not have enough probative value to warrant admissibility. See FED. R. Evid. 403 ("Although relevant, evidence may be excluded if its probative value is substantially outweighed by the danger of unfair prejudice, confusion of the issues, or misleading the jury, or by considerations of undue delay, waste of time, or needless presentation of cumulative evidence."). 
on proof of Learn: evidence of Statement has significant probative value given proof of Learn, but not absent proof of Learn. ${ }^{22}$

To be technically correct, therefore, we should ordinarily speak of conditional probative value rather than conditional relevance. ${ }^{23}$ And I will do so in this article. On the other hand, this point is not limited to conditional relevance and probative value. Most often, when a party objects to evidence as irrelevant, an objection that the evidence has insufficient probative value to warrant admission would be closer to the mark. Relevance may nevertheless be a satisfactory shorthand to express this issue in most circumstances. Similarly, conditional relevance may often be a workable-enough term to express the more precise concept of conditional probative value.

\section{INTERMEDIATE Factual Findings}

\section{A. The Nature of the Problem: Intrusion into the Fact-Finding Process}

A second problem in Rule 104(b) concerns the rule's overly formalized conception of the fact-finding process. The rule addresses the situation in which the relevance of the proffered item of evidence "depends upon the fulfillment of a condition of fact." It provides that in this situation the proffered evidence may be admitted if "evidence sufficient to support a finding of the fulfillment of the condition" is introduced. In Blanca's hypothetical, the rule would conceive of the relevance of evidence of Statement as depending upon the "fulfillment" of the "condition of fact" that proposition Learn is true, and so would make admissibility of the evidence of Statement dependent upon the presentation of "evidence sufficient to support a finding" of Learn.

Rule 104(b) does not state how definite the hypothesized finding must be. Does the evidence have to be sufficient to support a finding that Learn is more likely true than not, clearly and convincingly true, or true beyond a reasonable doubt? The Supreme Court

22. Cf. Nance, supra note 9, at 475 ("[L]egitimate exclusion of relevant evidence for waste of time may occur under the rubric of conditional relevance."). On the other hand, in some cases a court might conclude that even without proof of Learn, the probability of Learn is sufficiently high, or at least a jury might so find, that Statement has significant probative value. This situation might occur, for example, if the document in question were a bannerheadline story in a widely circulated newspaper. See infra section IV.A.1.

23. Nance uses this term tentatively and briefly. See Nance, supra note 9, at 473 . Those cases to which the conditional relevance label would apply - because the proffered evidence would be irrelevant without proof of the predicate proposition, see supra note 20 and accompanying text - would also be cases of conditional probative value; the latter is a more inclusive term. 
has, however, endorsed the "preponderance," or more-likely-thannot, standard, ${ }^{24}$ and this does seem to be the intended one. I believe that, using this standard, Rule 104(b)'s requirement of "evidence sufficient to support a finding" is, in any given case, either redundant or artificially restrictive of the jury's role. Moreover, if a more stringent standard is used, the more serious of these problems, that of artificial restrictiveness, will be aggravated.

Suppose first that, as a matter of substantive law, Proffer, the proponent of the evidence, must prove Knew or suffer dismissal of his case. ${ }^{25}$ Suppose further that, apart from the possibility that both Statement and Learn are true, Proffer offers no plausible story in which Knew is true. If, when Proffer's evidence is all in, the jury could not reasonably make a finding of Learn, then one could say that the evidence of Statement has little or no probative value. But at the same time, it would be clear that Proffer's case was insufficient to go to the jury. Holding that evidence of Statement is irrelevant absent sufficient evidence of Learn does not add anything useful when we know that the proponent's whole claim or defense is inadequate absent sufficient evidence of Learn. ${ }^{26}$

Some of the cases discussed by traditional authorities to illustrate conditional relevance present this redundancy, ${ }^{27}$ and Dale

24. Huddleston v. United States, 485 U.S. 681,690 (1988) ("In determining whether [the proponent] has introduced sufficient evidence to meet Rule 104(b), the trial court . . . simply examines all the evidence in the case and decides whether the jury could reasonably find the conditional fact . . . by a preponderance of the evidence.").

25. In the case as I have posed it, Proffer is a prosecutor and Knew is an element of the crime charged. The same essential analysis would hold with respect to a civil plaintiff and an element of her claim, or to a civil or criminal defendant and an element of her defense.

26. See Allen, supra note 10, at 873; Ball, supra note 6, at 442; Nance, supra note 9, at 454.

27. For example, in Coghlan v. White, 128 N.E. 33 (Mass. 1920), notice to the defendant was a condition precedent to recovery by the plaintiff. The trial court excluded evidence of notice that was proper in form because it found that service was not made properly. As a necessary consequence of that ruling, the court directed a verdict for the defendant. $128 \mathrm{~N}$.E. at 33-34. The appellate court reversed, holding that the question whether service was made as required was for the jury. 128 N.E. at 35. Coghlan is discussed in 1 Edmund M. MoraAn, Basic Problems of Evidence 48-49 (1961). Another example is Gila Valley, Globe \& Northern Railway v. Hall, 232 U.S. 94 (1914). There, the defendant presented a defense of assumption of risk by offering testimony that a declarant, in the somewhat distant presence of the plaintiff, spoke of the injury-causing defect in a wheel. 232 U.S. at 102-03. The Court held - incorrectly - that the question whether the plaintiff heard the statement should have been resolved by the trial judge. 232 U.S, at 103. Gila Valley is discussed in Morgan, supra note 1, at 172, and in WeINSTEIN, supra note 1, $9104(09)$, at 104-105. Note that in Gila Valley, although the evidence was offered by the defendant, rather than the plaintiff, the basic redundancy was the same: the basis for the defense of assumption of the risk was the contention that the plaintiff knew of the defect, and the basis for that conclusion was the evidence of the declarant's assertion in the vicinity of the plaintiff; hence, if there was no basis for concluding that the plaintiff heard the declaration, there was no need to submit the defense of assumption of the risk to the jury. 
Nance exposes it nicely. ${ }^{28}$ But other cases do not present this redundancy. That is, the following propositions may both be true in a given case: (i) the proponent would not lose the claim or defense as a matter of law for failure to present evidence of a given predicate proposition, and (ii) the probative value of a proffered piece of evidence does depend to a significant extent on the presence of evidence of that predicate proposition.

When these conditions hold, the requirement that there be "evidence sufficient to support a finding" of the predicate proposition is not redundant. On the contrary, it imposes an artificial, and potentially harmful, restriction on the fact-finding process. The problem is that a rational jury, unrestrained by artificial restrictions, would not have to segment its fact-finding function in the manner apparently contemplated by Rule 104(b). In some circumstances, a jury might reasonably accord significant, even decisive, weight to a proffered item of evidence, conditional on there being some evidence making a predicate proposition plausible, even though the jury is not persuaded that the predicate proposition is true. Given that a finding, even implicit, by the jury of the predicate proposition is unnecessary to make the proffered evidence worthy of admission, it would be unduly restrictive, at least in the usual case, to admit the proffered evidence only if the evidence of the predicate proposition is "sufficient to support a finding." 29

Sections $B$ and $C$ of this Part discuss two basic settings in which the conditions stated above both hold. In these situations, the concept of conditional probative value is not redundant, but Rule 104(b)'s requirement of evidence "sufficient to support a finding" of the predicate proposition intrudes artificially into the fact-finding process. Section $\mathrm{D}$ then discusses a particular setting, the demand for authenticating evidence, in which there is a plausible - though not to my mind compelling - argument in favor of this artificiality. Section $E$ then argues that the very notion of a predicate proposition must be used with great care. The actual predicate for the proffered evidence is any of a wide variety of potential items of evidence, and speaking of a predicate proposition is a shorthand

28. See Nance, supra note 9, at 454 ("Of course, if a proponent cannot present sufficient evidence to support a finding on one of the essential elements of the proponent's cause of action or affirmative defense, then presentation of evidence on the other elements becomes pointless.").

29. See Nance, supra note 9, at 451 ("[T]he trier [of fact] must make a finding, by the appropriate standard of proof, only as to the ultimate propositions in the case, not as to intermediate evidentiary propositions contained within inferential chains."); id. at 459-62, 471-72 (analyzing cases in which the artificial requirement of evidence sufficient to form a finding of a preliminary fact may have resulted in the exclusion of valuable evidence). 
way of referring in the aggregate to this ungainly set of evidentiary items.

\section{B. Disjunctive Reasoning}

Consider again Blanca's hypothetical, in which the proponent of the evidence is trying to prove Knew, the proposition that Blanca knew that the conduct in which she allegedly engaged was illegal. As before, let Statement refer to the proposition that the prohibition was stated in a document created before the time of the alleged conduct and Learn to the proposition that before that time Blanca learned the contents of the document. For now, suppose that the document was a front-page story of a small-circulation newspaper. Suppose also that Watchtelecast is the proposition that Blanca watched a television newscast during which the prohibition was announced, and that there is sufficient evidence to make Watchtelecast at least plausible.

Thus, the truth of Knew is not dependent solely on the truth of Statement-and-Learn: if either Statement-and-Learn or Watchtelecast is true, then Knew is probably true. This is therefore a case involving disjunctive reasoning. A juror would be perfectly reasonable in reaching the conclusion that Knew is probably true in this way:

If evidence of Watchtelecast were the only proof of Knew, I'd conclude that Knew is false, because I believe that Watchtelecast is more likely false than true, though it's a close call. But even if Watchtelecast isn't true, Knew is probably true if Statement-and-Learn is true, and I'm very confident that Statement is true. I believe that Learn is more likely false than true, but again it's a close call. Taking everything into account, I believe it's substantially more likely than not that either Statement-and-Learn or Watchtelecast is true, or both. This means that Knew is probably true. ${ }^{30}$

30. To take a numerical example, suppose that

Probability (Watchtelecast) $=.4$,

Probability $($ Learn $)=.4$,

Probability (Statement) $=.9$,

and that these probabilities are independent.

Probability (Watchtelecast or (Statement and Learn)) can be calculated by indirection: Watchtelecast or (Statement and Learn) is true if and only if Not Watchtelecast and Not (Statement and Learn) is not true. Therefore,

Probability (Watchtelecast or (Statement and Learn)) $=1$ - Probability (Not Watchtelecast Now, and Not (Statement and Learn)). and

Probability (Not Watchtelecast) $=1-.4=.6$,

Probability (Statement and Learn) $=(.4) \times(.9)=.36$,

which means that

Probability (Not (Statement and Learn)) $=1-.36=.64$. 
Note that in this case evidence of Statement, taken in conjunction with evidence of Learn, clearly has substantial - indeed, decisive - probative value, even though the juror does not believe Learn to be true. Though some evidence of the predicate Learn is necessary in this case for the proffered evidence of Statement to have substantial probative value, a "finding" of the predicate, even an implicit one, is not. Thus, if the court were to exclude the proffered evidence unless the predicate is supported by sufficient evidence to support a finding, useful evidence would unnecessarily be kept from the jury.

There is an interesting symmetry between this disjunctive situation and the more frequently discussed case of conjunctive proof of elements of a crime, claim, or defense. ${ }^{31}$ The issue of conjunction arises when a crime, claim, or defense requires the conjunction of two or more elements - that is, when it requires that all the elements be true. The supposed difficulty is that the fact finder may be persuaded that the conjunction of the elements is more likely false than true even though it is persuaded that each of the elements is more likely true than false. In the disjunctive situation discussed in this article, the fact finder can conclude that a disjunctive proposition is more likely true than false even though it is persuaded that each of the alternatives constituting the disjunction, or any subset of them, is more likely false than true. Logically, the conjunctive and disjunctive situations are essentially identical - perfect reflections of each other. ${ }^{32}$ Thus, my solution to both the disjunctive and

\section{Therefore,} and

Probability (Not Watchtelecast and Not (Statement and Learn)) $=(.6) \times(.64)=.384$,

Probability (Watchtelecast or (Statement and Learn)) $=1-.384=.616$, which is substantially more likely than not.

More generally, a proposition ( $A$ or $B$ or ... or $N$ ) may be more likely true than false even though one or more of the individual propositions, $A, B$, and so on, is more likely false than true - indeed, even though each of those propositions is more likely false than true. See Nance, supra note 9, at 450-51 (arguing that in proving notice from an utterance, "there could be evidence of a variety of events, different in nature and weakly probative taken severally, that taken in combination make the existence of notice very likely but do not make it likely that the particular utterance was heard").

31. See, e.g., Richard D. Friedman, Infinite Strands, Infinitesimally Thin: Storytelling, Bayesianism, Hearsay and Other Evidence, 14 CARDozo L, REv. 79, $96-99$ (1992); Ronald J. Allen, Factual Ambiguity and $a$ Theory of Evidence, 88 Nw. U. L. Rev. 604, 605-12 (1994); see also infra note 32. that

32. The conjunctive issue is presented by the fact that for propositions $A$ and $B$, it may be

(1) Probability $(A)>.5$ and but

(2) Probability (B) $>.5$,

(3) Probability $(A$ and $B)<.5$. 
conjunctive situations is similar: Avoid artificial segmenting of the fact finder's function. ${ }^{33}$

\section{The Proponent Without the Burden of Persuasion}

In at least one other basic situation, the jury may reasonably accord significant weight to proffered evidence conditional on the presence of some evidence of a predicate proposition, even though the jury is not persuaded that the predicate proposition is true. This occurs when the proponent of the proffered evidence does not bear the burden of persuasion with respect to the proposition on which that evidence bears.

\section{Consider the following hypothetical:}

Acuff's hypothetical: Acuff, accused of murder, acknowledges that the victim was murdered but denies that he committed the murder. Constitutionally, the prosecution must bear the burden of proving beyond a reasonable doubt that Acuff was the perpetrator. The prosecution presents an eyewitness who testifies that the murder occurred at 10:30 on the evening of June 11 and identifies Acuff as the murderer. In addition to cross-examining this witness, Acuff presents evidence of an alibi. Witness Restick offers to testify for Acuff that Acuff was in her bar continuously between 9:00 and 11:30 one evening

The disjunctive issue is presented by the fact that for propositions $C$ and $D$, it may be that

(4) Probability (C) $<.5$ and but

(5) Probability (D) $<.5$,

(6) Probability ( $C$ or $D)>.5$.

It can be demonstrated rather quickly that the set of inequalities (1), (2), and (3) is the logical equivalent of the set of inequalities (4), (5), and (6). Note first that any proposition $X$ can be expressed as the negative of some other proposition; if $Y$ is defined to be Not $X$, then $X$ equals Not $Y$. See generally Kevin W. Saunders, The Mythic Difficulty in Proving a Negative, 15 Seton Hall L. Rev. 276 (1985). We can therefore define $C$ as equal to NotA, and $D$ as equal to NotB. Thus, Probability $(C)=$ Probability $($ NotA $)=1-$ Probability $(A)$, which means that Probability $(A)=1$ - Probability $(C)$. Thus, inequality (1) means that 1 Probability $(C)>.5$; this is the equivalent of inequality (4). By similar steps, inequality (2) can be shown to correspond to inequality (5). Finally, because the proposition $A$ and $B$ is identical to NotC and NotD, and so also to Not(C or D), inequality (3) may be rewritten as Probability $(\operatorname{Not}(C$ or $D))<.5$, or as 1 - Probability $(C$ or $D)<.5$, and this plainly yields inequality (6).

33. See Friedman, supra note 31 , at 97 . Allen continues to insist that my treatment of the conjunction problem "has the odd consequence of relatively favoring plaintiffs (including the state) or defendants as a function of the number of the required elements." Allen, supra note 31 , at 607 . I continue to insist that this problem is illusory. See Friedman, supra note 31, at 97 n.50. In brief, if the substance of a claim is kept the same, dividing it into more elements simply means that there is less content in each element. To paraphrase Al Smith's famous line ("no matter how thin you slice it, it's still baloney"), no matter how thin you slice a piece of baloney, it's still the same size. Moreover, the elements are not independent. Thus, if what might be thought of as one element (no notice of a fact given at any time during the period Day 1 through Day $n$ ) is instead broken into many narrower elements (no notice given on Day 1, no notice given on Day 2, and so on), satisfaction of one of the narrower elements will tend to make others more probable. 
in June; she does not remember which evening, but she does remember that Acuff arrived around the same time as Waters.

Without evidence determining the date that Acuff was purportedly in the bar, Restick's testimony has little probative value. But now suppose the following:

Additional evidence for Acuff: Waters testifies that she was in Restick's bar on the night of the murder and on no other night during the entire year; she remembers this, she says, because she remembers hearing about the murder the next day.

A juror might reasonably analyze the situation as follows:

Absent evidence to the contrary, I'd probably conclude beyond a reasonable doubt, on the basis of the eyewitness testimony, that Acuff was the murderer. But I have to take the evidence presented by Acuff into account. I tend to believe Restick's testimony. That in itself doesn't create a reasonable doubt because Restick doesn't remember what date Acuff was in her bar. Waters's testimony, if true, does provide the date. I tend to disbelieve Waters's testimony, but it might be true. If both Restick and Waters are telling the truth, then Acuff couldn't be the murderer. I therefore have a reasonable doubt as to whether Acuff was the murderer. The judge has instructed us that we cannot find him guilty unless the prosecution persuades us beyond a reasonable doubt that he was the murderer, and so I vote to find him not guilty.

Note that the critical aspect of this juror's reasoning is not a matter of disjunctive logic; 34 the only basis for doubt that she has expressed is the possibility that Acuff was in the bar on the night of the murder. But in order to find a reasonable doubt that Acuff committed the murder, she only has to believe that it is plausible not that it is more likely than not, and a fortiori not that any more stringent standard has been met - that Acuff was in the bar on that night.

\section{Authentication}

The requirement of authentication - showing that a piece of evidence is what its proponent claims it to be - is, according to the standard account, an aspect of conditional relevance. ${ }^{35}$ If, for example, a party contends that a letter purporting to be by Blanca acknowledges that her alleged conduct was prohibited, the letter

34. I hesitate to make a broader statement - that the juror is not using disjunctive logic - because any possibility that the juror might consider may be thought of as a disjunction of more narrowly defined possibilities. See supra section II.B.

35. In its Note to Rule 901, the Advisory Committee said: "This requirement of showing authenticity or identity falls in the category of relevancy dependent upon fulfillment of a condition of fact and is governed by the procedure set forth in Rule 104(b)." FED. R. EvID. 901 advisory committee's note. 
will have little or no probative value in showing Blanca's knowledge of the prohibition if in fact she did not write it. Thus, Federal Rule of Evidence 901 enunciates the same standard as Rule 104(b), providing that the authentication requirement "as a condition precedent to admissibility is satisfied by evidence sufficient to support a finding that the matter in question is what its proponent claims."36

Because the problem of authentication is a facet of the broader problem I call conditional probative value, the same considerations apply: a fact finder might rationally accord substantial probative value to a piece of evidence even without believing that the evidence is what the proponent claims it to be. Sometimes a plausible possibility will suffice. Moreover, in some cases the basis for that belief may well be provided by the evidence itself, without the need for independent evidence showing that it is what the proponent claims. ${ }^{37}$ Thus, strictly as a matter of rational evaluation of the evidence presented, the standard of "evidence sufficient to support a finding" is too stringent.

But perhaps there is more at stake than evaluation of the evidence presented to the fact finder. There is a dynamic aspect also to be considered: How will the rules affect what evidence will be presented to the fact finder? In two respects, requiring evidence sufficient to support a finding of authenticity might improve the quality of the evidence presented at trial, ${ }^{38}$ especially if the requirement is construed with some persnicketiness. ${ }^{39}$

\section{FED. R. Evid. 901(a).}

37. The Federal Rules do recognize this possibility. See FED. R. Evid. 901(b)(4) (approving authentication by distinctive characteristics and the like); FED. R. EvID. 902 (approving self-authentication).

38. Dale Nance, in a powerfully argued article, takes this view:

The extent to which the doctrines now assimilated under the rubric of conditional relevance make sense is attributable to [the best evidence] principle. It rests upon considerations not of the logic of relevance, but rather of a protective evidentiary principle. In some cases the purpose of this reinterpreted doctrine of conditional relevance is to encourage the presentation of additional evidence rather than to exclude that which is originally proffered. Here, the doctrine can be seen as a manifestation of the expansionary dimension of the best evidence principle, enforced by an exclusionary rule. In other cases, where the probative value of the original proffer is slight without more, exclusion upon failure to present further information may also be simply an effort to avoid a waste of the time and energy of the tribunal, manifesting the contractionary dimension of the best evidence principle.

Nance, supra note 9, at 505-06.

39. Indeed, in applying the standard, courts have traditionally been far more demanding than the ordinary mandates of common sense:

[I] $f$ the writing bears a signature purporting to be that of $\mathrm{X}$, or recites that it was made by $X$, we assume, nothing to the contrary appearing, that it is exactly what it purports to be, the work of $X$. At this point, however, the law of evidence has long differed from the commonsense assumption upon which each of us conducts her own affairs, adopting instead the position that the purported signature or recital of authorship on the face of a 
First, such a requirement might make manufacture of fraudulent evidence significantly more difficult. ${ }^{40}$ This consideration does not deserve very great weight, however. The authentication requirement does not exclude all fraudulent evidence, because if it is possible to manufacture fraudulent primary evidence, it will often be possible to manufacture fraudulent authenticating evidence as well. Moreover, if the primary evidence is genuine, an overly stringent authentication requirement will cause an unnecessary cost either in money and time or in probative value. ${ }^{41}$ So far as the possibility of fraud is concerned, it would be better to adhere to the easier standards that should govern other cases of conditional probative value and leave the detection of fraudulent evidence to the usual processes, which depend on the adversary's inquiries and the fact finder's common sense.

Second, when the proponent is able but not inclined to present evidence of the predicate, the authentication requirement encourages her to do so, for if she does not she suffers inadmissibility of the evidence. In most cases, this also should not be a very powerful concern: the proponent who does not present predicate evidence weakens her case, and the opponent has the opportunity to present evidence contesting authenticity. Thus, usually the parties' own incentives will address the problem suitably. But occasionally, these incentives may be inadequate. It may be that the evidence bearing on the authenticity question tends to disfavor the proponent, but for some reason the opponent's access to this evidence is not nearly as good as the proponent's. Only in such limited circumstances when authenticity is genuinely in doubt, and the proponent has substantially better access to evidence bearing on the question of authenticity - should an authentication requirement be imposed on the proponent. Even then, as I show in Part V, this can be done without introducing the artificiality of intermediate fact-finding.

writing will not be accepted as sufficient preliminary proof of authenticity to secure the admission of the writing in evidence.

MCCORMICK ON EVIDENCE $\$ 218$, at 37 (J. Strong ed., 4th ed. 1992); see also In re Dodd, 82 B.R. 924,929 (N.D. Ill. 1987) (holding the mere assertion by a telephone caller of an institutional affiliation insufficient to authenticate a telephone conversation).

40. See MCCORMick on Evidence, supra note 39, $\$ 218$, at 38 ("The principal justification urged for this judicial agnosticism toward the authorship of documents is that it constitutes a necessary check on the perpetration of fraud.").

41. See id. at 38 ("[R]equiring proof of what may correctly be assumed true in 99 out of 100 cases is at best time-consuming and expensive. At the worst, the requirement will occasionally be seen to produce results which are virtually indefensible."). 


\section{E. The Nature of the Predicate}

In the classical model of conditional relevance, as exemplified by Rule 104(b), the relevance of the evidence in question depends upon the truth of a predicate proposition, and the admissibility of the evidence depends upon the sufficiency of evidence to support a finding of that predicate proposition. As I have discussed Blanca's hypothetical, for example, Learn - the proposition that by a given time Blanca learned of the contents of the document in questionis the predicate on which the admissibility of Statement might depend.

Note, however, the care that must be taken in defining the predicate proposition. For example, a proposition narrower than Learn - such as Read, that Blanca actually read the document - would be inadequate as the predicate; Statement clearly has substantial probative value with respect to Knew even if it is shown that Blanca learned the contents of the document without reading it. But neither is Learn trouble-free as the predicate. First, there is at least some ambiguity in Learn as I have defined it. Does it mean that Blanca must have learned all the contents of the document, or only of its assertion of the key fact Prohib, or perhaps only of information - for example, a summary headline - suggesting that the document asserted Prohib? Second, perhaps Learn itself is too narrow; perhaps it would be enough if Blanca learned information suggesting that some document asserted Prohib without knowing precisely what document that was. The exact bounds of the predicate proposition probably depend to some extent on the exact nature of the proffered evidence; for example, the predicate might differ depending on whether the proffered evidence is that the document asserted Prohib in a screaming headline or deep within a mass of fine print.

Perhaps these problems could be resolved by very precise attention to the particular matter at hand. But I think they probably cannot be, and there is probably no need to resolve them because emphasis on the predicate proposition as such is misplaced. Rather than speaking of a predicate proposition, a court might say quite simply, for example, that a proffered piece of evidence will have substantial probative value if a given predicate piece of evidence is offered as well. This manner of speaking not only avoids the difficulty of defining the predicate proposition but also involves the least degree of intrusion possible on the fact-finding process because it deals only in the evidence and not at all in any intermediate factual propositions. 
This raises a complication, however. A myriad of different evidentiary items, or groups of items, may suffice as the predicate for the proffered evidence. The court cannot anticipate all of them, nor can it necessarily even articulate a categorization to group them together - except by reference to some proposition that each of them tends to support. For example, in Blanca's hypothetical, the testimony of any witness that he observed Blanca reading the document in question, or of a second witness that she observed the document in a place where Blanca was sure to see it, or of a third witness that she heard a discussion of the document that Blanca was likely to hear, is likely to be a sufficient predicate for the proffered evidence of what the document said. Note, moreover, that each witness's testimony is a different evidentiary item from each other witness's. And there may be other items of evidence as well that would be satisfactory predicates. The most concise way to refer comprehensively to all these items of evidence, it seems, is to speak in terms such as "evidence supporting the proposition that Blanca learned of the contents of the document."

Thus, even if the predicate proposition is ill-defined, it provides a useful shorthand for referring to the universe of evidence that may be a satisfactory predicate for the proffered evidence. When I speak of a predicate proposition, therefore, this "proposition" generally does not represent one possible predicate item of evidence for the proffered evidence but rather a broad, open, and perhaps unshapely set of possibilities.

\section{Defining Conditional Probative Value}

Up to this point, I have concentrated on problems of the classical concept of conditional relevance. This Part will develop and attempt to show the usefulness of the more fluid concept of conditional probative value. To do so requires first some attention to the nature of probability.

The probability of a proposition refers to an evaluator's subjective level of confidence in the truth of the proposition. That assessment is not made in a vacuum. When we speak of the probability of a given proposition, we must either state or assume implicitly the base of information on which the probability is assessed. Thus, to be precise, we should never speak merely of Probability $(X)$, the probability of proposition $X$. We must at least take into account $O$, the body of knowledge of the world possessed by the person or entity assessing the probability. To be explicit, we must speak in terms at least as complicated as Probability ( $X$ given $O)$; if we want 
to consider the probability of $X$ assuming proposition $A$, then precision demands that we speak in terms such as Probability ( $X$ given $A$ and $O$ ). All probability, then, is conditional, no matter to what extent the conditions are made explicit.

Assessing the probative value of a piece of evidence with respect to a proposition calls for a comparison of two probabilities: the probability of that proposition with and without the evidence included in the base of information. ${ }^{42}$ That base of information will also include the rest of the evidence introduced in the case. To refer to the inclusion of a given piece or body of evidence within the base of information, I will refer to an evidentiary proposition; evidentiary proposition $A$ is the proposition that evidence of description $A$ has been introduced. But the base of information is not limited to evidence actually introduced. It also includes the knowledge that the fact finder may validly bring with it from the outside world; jurors are not required to come to court as blank slates. ${ }^{43}$ Thus, in determining the probative value of evidentiary proposition $A$ with respect to material proposition $X$, we must compare

\section{Probability ( $X$ given $E$ and $O$ ) and}

\section{Probability ( $X$ given $A, E$, and $O$ ),} where the first of these terms represents the probability of $X$ given all the other Evidence introduced in the case and all the Other knowledge the fact finder may validly use, and the second represents the probability of $X$ given all that and also given $A$. To the

42. Several years ago, I engaged in a friendly debate with David Kaye over how best to define probative value formally. See Richard D. Friedman, $A$ Close Look at Probative Value, 66 B.U. L. REv. 733 (1986); D.H. Kaye, Quantifying Probative Value, 66 B.U. L. REv. 761 (1986); Richard D. Friedman, Postscript: On Quantifying Probative Value, 66 B.U. L. Rev. 767 (1986). That debate now strikes me, as it no doubt struck others at the time - assuming others paid any attention - as rather sterile. Nevertheless, $I$ continue to believe that the language of Rule 401 suggests a good basis for measuring the probative value of a piece of evidence with respect to a given proposition: a comparison of the probability of the proposition before and after introduction of the evidence.

43. See, e.g., 9 JOHN HENRY WIGMORE, EvideNCE $§ 2570$ (Chadbourn rev. ed. 1981); John H. Mansfield, Jury Notice, 74 GEo. L.J. 395, 406-07 (1985) (discussing what constitutes "common knowledge" that a jury may validly bring to bear on a case, and advocating a standard requiring "that a substantial number of people in the community have the information or hold the belief in question"); Richard M. Fraher, Adjudicative Facts, Non-Evidence Facts, and Permissible Jury Background Information, 62 IND. L.J. 333, 353 (1987) (challenging Mansfield's standard and advocating "the jury's traditional and useful function as an inscrutable 'black box" "); Allen, supra note 31, at 617 (arguing for a broad concept of evidence that includes, in addition to the "material adduced at trial," a "sufficient body of knowledge and sufficient intelligence to use it to appraise" that material); see also Jenney Elec. Co. v. Branham, 41 N.E. 448, 451 (Ind. 1895) (stating that jurors should use experience and education when evaluating evidence); Rostad v. Portland Ry. Light \& Power Co., 201 P. 184, 187 (Ore. 1921) (holding that jurors should consider testimony in light of common knowledge and experience). 
extent that these two probabilities are different, $A$ has probative value with respect to $X$.

Just as a determination of probative value requires a comparison of two probability assessments, a determination of conditional probative value requires a comparison of two determinations of probative value - one in which the base of information includes the predicate, and one in which the base does not include the predicate. $^{44}$

In this article, I will make that comparison in two different ways, corresponding to two different senses of conditional probative value, one more inclusive than the other. The broader sense is what I will term relative conditional probative value. To say in this sense that evidence $A$ has significant probative value with respect to proposition $X$ conditional on predicate $B$ means merely that $A$ has significantly greater probative value with respect to $X$ if $B$ is included in the base of information than if $B$ is not included. ${ }^{45}$ In other words, the difference between

\section{Probability ( $X$ given $A, E$, and $O$ )}

and

Probability ( $X$ given $E$ and $O$ )

is significantly less in absolute value than the difference between

and

Probability ( $X$ given $A, B, E$, and $O$ )

Probability ( $X$ given $B, E$, and $O){ }^{46}$

44. Most obviously, the predicate may be part of the base of knowledge because evidence satisfying the predicate is presented. Sometimes, however, there is a question whether the predicate is part of the base of knowledge that the fact finder may validly bring to court. The concept of conditional probative value may be applied to this case. See infra text following note 50 .

45. Recall that $B$ may be a disjunctive set of evidentiary possibilities; accordingly, $B$ would be in the base of information if any of the evidentiary items forming one of the elements of that set is presented to the fact finder, For that matter, one element of $B$ may be a proposition that is arguably within the base of knowledge that the fact finder may validly bring from the outside world. See supra note 43 and accompanying text. Hence, we may refer to $O$ as being the base with that element included and $O^{\prime}$ as being the base without that element included. See infra paragraphs preceding note 47.

46. What if the first difference is significantly greater than the second difference? An even broader definition would include this as a situation of conditional probative value, because the probative value of the proffered evidence has been affected - diminished - by the predicate. I prefer thinking of this as the opposite of conditional probative value. Most often, this situation will arise when evidence $A$ is cumulative given evidence $B$. For example, evidence that a car has a Chevrolet hubcap on its left front wheel is generally probative evidence that the car is a Chevrolet, but it will have much less probative value if evidence has already been admitted that the car bears the imprint of a Chevrolet serial number. Sometimes evidence $B$ diminishes the probative value of evidence $A$ for the opposite reason: $B$ may point in the opposite direction from $A$, and with overwhelming strength. Thus, the Chevrolet hubcap probably has little probative value in the face of evidence that a Ford serial number is imprinted on the car. 
In Part V, I will discuss one potentially significant application of this broad sense of conditional probative value. For the most part, however, a special case - a more restrictive sense of conditional probative value - will be pertinent to the discussion. I will use the term near-absolute conditional probative value to describe this special case, because the essence of it is that not only does the proffered evidence have greater probative value given the predicate than absent the predicate, but absent the predicate the proffered evidence has very little probative value at all, too little to warrant admissibility. In other words, evidence $A$ has significant probative value with respect to proposition $X$ conditional on $B$ in this narrower sense if (i) $A$ does not have significant probative value with respect to $X$ if $B$ is not included in the base of information, but (ii) $A$ does have significant probative value with respect to $X$ if $B$ is included. . Or, in the semisymbolic style used above:

If

(i) Probability ( $X$ given $A, E$, and $O$ ) is not significantly different from Probability ( $X$ given $E$ and $O$ ), but

(ii) Probability ( $X$ given $A, B, E$, and $O$ ) is significantly different from Probability ( $X$ given $B, E$, and $O$ ), then

$A$ has significant probative value (in the stronger, nearabsolute sense) with respect to $X$ conditional on $B$.

$B$ is not necessarily an evidentiary proposition or a proposition that requires evidentiary proof. It may instead be a proposition that is arguably within the body of information that the jury may bring from the outside world. If we substitute $O^{\prime}$ for $O$ in the above definitions, where $O^{\prime}$ represents a base of information identical to $O$ except that it definitely does not include $B$, then the definitions may be used to articulate the circumstances in which, in either of the two senses, $A$ has significant probative value with respect to $X$ conditional on $B$ being within the jury's valid base of outside information.

Under either definition, there is a two-sided aspect to the determination of conditional probative value: Absent $B, A$ has relatively low probative value - insignificant probative value, if the case fits the restrictive sense of conditional probative value - but, given $B$,

Note that the reference in the above definition to the absolute value of differences is meant to address one potential complexity. Suppose that absent $B$ evidence $A$ tends to alter the probability of $X$ in one direction, but that given $B$ evidence $A$ tends to alter the probability of $X$ in the other direction. It seems to me that in this circumstance it is best to say that $A$ has significant probative value with respect to $X$ conditional on $B$ if the second effect is significantly greater in absolute value than the first effect. 
$A$ does have significant probative value. This two-sided aspect is what makes the probative value conditional.

Note that the conditionality involved here is not of the same type, or on the same plane, as that involved in conditional probability. Again, all probabilities are conditional; it is meaningless to speak of the probability of a proposition in the abstract, without at least implicit reference to the set of assumptions determining the context in which the probability assessment is made. But a conditional probability is not a comparative assessment. Stating an assessment of the probability of proposition $X$ assuming the truth of - that is, conditioned on - proposition $A$ and the reservoir of propositions labeled $O$ does not reveal what the probability of $X$ would be if $A$ were not true. That type of assessment - a conclusion, for example, that $X$ is significantly more probable assuming the truth of $X$ than absent that assumption - is one of probative value, a comparison of two probabilities. A statement of conditional probative value is a comparison of two determinations of probative value - requiring four probability assessments.

It is the court that determines probative value, or conditional probative value, in making admissibility decisions. But it is the jury that will eventually decide the probability of disputed propositions on whatever state of evidence is presented to it. Therefore, if the court is acting with rigor, the probability assessments that it uses in making determinations of probative value should not be its own. Rather, it should try to gauge the assessments that a reasonable juror might make. But, given that all probability assessments are subjective, the assessments made by different reasonable jurors might differ greatly. Which type of reasonable juror should the court hypothesize? For most purposes, I think the court should probably be thinking of the juror whose probability assessments are affected by the evidence to the greatest extent reasonable. Thus, the court should not conclude that evidence has low probative value if a reasonable juror might find the evidence highly persuasive.

There is a sense in which all probative value, as well as all probability, is conditional, and not on only one predicate but on many. ${ }^{47}$ Even if no other evidence is necessary for $A$ to have pro-

47.

No evidence is simply relevant in its own right. Evidence is relevant only because there is an intermediate premise or set of premises that connects the evidence to some proposition involved in the litigation. But if determining the relevance of evidence always requires relying on some intermediate premise, no distinction can be drawn between relevancy and conditional relevancy.

Allen, supra note 10 , at 877 (citation omitted). 
bative value with respect to $X$, that probative value will be conditional on some propositions that may be within the base of information that the jury may bring in from the outside world. A simple example makes the point: It seems obvious that the fact that it is cloudy in a city one morning has probative value with respect to the proposition that it will rain in that city in the afternoon. But that probative value is conditional on some propositions, such as the proposition that the city, and for that matter the earth, will exist in the afternoon, and that the weather will not be so cold that rain is impossible. We may not focus on these predicates if they are clearly within the base of information that the jury may import from the outside world. Analytically, though, they are among the factors conditioning the probative value of the evidence of the morning clouds.

Thus, I agree with Professor Allen, not only that assessing conditional probative value requires the same type of determination that assessing ordinary probative value does, but also that all probative value is conditional. ${ }^{48}$ But Allen goes too far, concluding that "there is no independent scope for the concept of conditional relevancy." 49 I believe that Allen overlooks, or at least shrugs aside, two important points.

First, far from sapping usefulness from the concept of conditional probative value, the fact that all probative value is conditional focuses attention on the ever-present question: Conditional on what? Sometimes, the base of information on which the jury may operate, information both from the outside world and from evidence, is in material respects fixed and undebatable, so that any predicate that might have a bearing on the probative value of the proffered evidence is either clearly inside or clearly outside that information base. In such a case, there is no substantial need to make an assessment of conditional probative value. But, of course, that will not always be the case. Often, when the bounds of the permissible base of information are unclear or disputable, it becomes important to determine the conditions under which the proffered evidence will have sufficient probative value to warrant admissibility.

Second, an assessment of conditional probative value stands on a different plane from an ordinary assessment of probative value because it is a comparison of probative value determinations.

48. See id. at $877-80$.

49. Id. at 880 . 
Again, assessing conditional probative value requires the same type of probative value determination to be made twice - once with the base of information including the predicate, and once with the base not including the predicate. This two-sided aspect is important in making conditional probative value a useful concept, both practically and analytically. A determination of conditional probative value effectively draws a line, setting forth different results on either side of the line and so too the consequences of crossing, or failing to cross, from one side of the line to another. As I will now argue, focusing on this conditionality may be important in various settings.

\section{Uses of the Concept of Conditional Probative VALUE}

\section{A. Analyzing the Structure of Probative Value}

Although the point is so deceptively simple it is easy to overlook, sometimes the concept of conditional probative value performs a useful service by assisting analysis of the conditions under which proffered evidence has probative value. Whether the court decides that the proffered evidence does or does not have enough probative value to warrant admissibility, the concept may help reveal the consequences of that decision, the vulnerable conditions underlying the decision, and the conditions under which the decision might plausibly change.

\section{Analyzing the Court's Probative Value Decision}

Recall Blanca's hypothetical, in which proof of Statement - the proposition that a document made a given statement by a prescribed time - may have sufficient probative value to warrant admissibility conditional on predicate Learn - the proposition that Blanca learned of the statement. Suppose that the document making the statement was a prominent article in a local newspaper. Suppose further that the proponent seeking to introduce the evidence of Statement offers, as proof of Learn, the transcript of testimony given by Whitney in a prior litigation that Blanca regularly read that newspaper thoroughly. The concept of conditional probative value might help an observer understand and analyze the trial court's decision whether to admit the evidence of Statement. That decision may depend on three subsidiary questions: 
(i) Absent the evidence of Whitney's prior testimony, does the evidence of Statement have sufficient probative value to warrant admission?

(ii) Given the evidence of Whitney's prior testimony, does the evidence of Statement have sufficient probative value to warrant admission?

(iii) Is the evidence of Whitney's prior testimony admissible under the exception to the hearsay rule for former testimony? ${ }^{50}$

Suppose first that the judge decides the first and second of these questions in the same way, either both in the affirmative or both in the negative. That is, whether the evidence of Statement has sufficient probative value to warrant admission or not, the determination is not conditional on Whitney's prior testimony. Assuming these conclusions lay properly within the judge's discretion, then the third question is moot, in one case because the evidence of Statement is admissible even if the prior testimony is not, and in the other case because the evidence of Statement is not admissible even if the prior testimony is.

But now suppose that the judge decides the first of the three questions in the negative and the second in the affirmative. Then Statement has substantial probative value conditional on the evidence of Whitney's prior testimony. This decision means that the hearsay question concerning the prior testimony is critical in determining admissibility of the evidence of Statement. Thus, if the trial court holds that the prior testimony fits within the hearsay exception, the appellate court might set up the problem in this way:

The trial court concluded that the evidence of the newspaper article had sufficient conditional probative value, conditional on the admissibility of Whitney's prior testimony. This ruling was within the trial court's discretion. But the question of whether Whitney's prior testimony avoids the rule against hearsay presents legal issues that we can decide. If we decide that the trial court erred on that issue, we should reverse; the admission of Whitney's prior testimony, which merely provided the predicate for the evidence of the newspaper article, was not in itself harmful error, but the trial judge was clearly correct that absent that predicate, the evidence of the newspaper article had too little probative value to warrant admissibility. If, on the other hand, we decide that the trial court ruled correctly on the hearsay issue, we should give effect to its conclusion that given Whitney's prior testimony, the evidence of the newspaper article had sufficient probative value to warrant admissibility.

In short, the concept of conditional probative value may help the court itself and any other observer to focus on the premises of

50. See, e.g., FED. R. Evid. 804(b)(1). 
the court's assessment of the probative value of the evidence, and, as a corollary, on the consequences of treating any of those premises as incorrect. In the illustration just discussed, the salient premise was the admissibility of a piece of predicate evidence. But this is not necessarily so: the premise under examination may have to do with what assessments the jury can make even absent evidence on a given point.

Consider this variation on the same illustration. The document making the announcement was not only a prominent article but a screaming headline story in the local newspaper. No other evidence is admitted tending to prove that Blanca learned of the story. The trial court might reason as follows:

The evidence of the newspaper article has significant probative value conditional on the jury's having a reasonable basis to conclude that it was at least substantially probable that Blanca learned of the story. I believe that the jury might very well conclude, even in the absence of evidence on the point, that Blanca was likely to read this story or hear about it promptly. After all, the jury is entitled to take notice of the facts that the Clarion is the leading newspaper here, that most households receive it, and that a given resident of town is very likely to notice an article of this prominence or at least to hear discussion about it. On that basis, I hold that the evidence of the newspaper article has sufficient probative value to warrant admission. But if I am wrong about what the jury can conclude on the basis of its own knowledge, then as matters now stand the evidence of the newspaper article should not be admitted.

Alternatively, the judge might reason:

Yes, the evidence of the article would have significant probative value if the jurors could validly regard the proposition that Blanca learned of the article as sufficiently probable. But, screaming headline or not, I don't believe that they could do so in this case absent evidence.

Whichever conclusion the judge reaches, she has revealed the structure of her decision: Whether the proffered evidence has enough probative value to warrant admission depends on whether a given proposition is one that the jury can treat as sufficiently probable even in the absence of evidence on that proposition.

\section{Altering the Status of the Evidence}

a. Linking Up. In the last variation of Blanca's hypothetical, the court ruled that the evidence of Statement would be significantly probative if the jury could reasonably regard Learn as sufficiently probable. But it also ruled that on the state of the evidence the jury could not do so. Such a case illustrates the "linking up" situation, in which courts make a very common and useful application of the 
concept of conditional probative value. In general, a party offers evidence $A$ that does not yet have sufficient probative value to warrant admissibility but would if she introduced evidence $B$. The offering party promises to link up the proffered evidence with other evidence later in the case. The judge might rule in either of two ways, either excluding the evidence subject to later admitting it or admitting it subject to later striking it. The judge might take the first option by saying something like,

I don't think that on the current state of the evidence the item you are offering has sufficient probative value to warrant admission. But if you could present evidence $B$, then the situation would be different, and presumably the evidence you are now offering would have enough probative value to warrant admission. like,

Or the judge might take the second option by saying something

O.K., I'll let this evidence in, on your promise to link it up, but if for any reason you don't provide evidence $B$ (or other suitably linking evidence), or if for any reason that linking evidence itself later turns out to be inadmissible, I'll have to strike this evidence.

b. Opening the Door. In the "linking up" situation, the proponent who offers evidence $A$ also offers the predicate evidence $B$. But that need not be so. It may be that the opponent "opens the door" by offering evidence $B$. Consider the following hypothetical, drawn from an actual case that I observed.

Akers is accused of raping Comstock, whom he had dated. Akers's attorney asserts in his opening that Akers and Comstock had consensual sex. As part of the prosecution's case-in-chief, Comstock testifies as to her version of the encounter. Comstock is also willing to testify that she hesitated to report the rape because she was reluctant to put herself through the ordeal of testifying at a rape trial, but that once she heard a credible rumor that Akers had raped another woman he dated, she decided to press charges to stop him from committing any more rapes. Akers's attorney moves to suppress this additional testimony. The judge rules as follows:

First, this testimony is inadmissible to prove that Akers raped the other woman, because on that basis it is both hearsay and propensity evidence. ${ }^{51}$ Second, there is a grave possibility that if I admit the testimony the jury will use it, no matter what my instructions, to conclude that the accused more likely committed the crime in question

51. The propensity objection may no longer be availing in cases involving sex crimes in federal courts as a result of recent legislative action. See Violent Crime Control and Law Enforcement Act of 1994, Pub. L. No. 103-322, § 320935, 108 Stat. 1796, 2135-37 (adding a new Rule 413 to the Federal Rules of Evidence subject to amendment by the Judicial Conference of the United States). 
because he committed the other one. Given the inadmissibility of the evidence on that basis, this use of the testimony would be highly prejudicial. Third, although the testimony may have some probative value in tending to show that Comstock pressed the charges here because she believed that she had been raped, this probative value is too slight to warrant admission of the evidence given the almost certain prejudicial impact. Therefore, I grant the accused's motion to exclude this testimony.

That is all the judge need do to rule on the motion. But the judge might add this caution to defense counsel:

Counselor, in pretrial proceedings you've emphasized that thirty-eight days passed between the encounter and the time that Ms. Comstock brought the rape charge, and you have suggested that her real reason for bringing the charge after that time was that she was disappointed when she realized that Akers didn't intend to have a continuing relationship with her. Now I'm warning you: If in front of the jury you emphasize the thirty-eight-day lapse, I will regard the probative value of the challenged evidence as substantially enhanced and will reconsider its admissibility. Moreover, if you present any evidence tending to show, or if you even make any hint, that Ms. Comstock had any ulterior motive in pressing the charge after the thirty-eight days, I will almost certainly regard the probative value of the challenged evidence as great enough to warrant admissibility for the limited purpose of showing her motive. Think very carefully before opening that door.

Suppose that the accused does open the door by presenting evidence of an ulterior motive. Suppose further that the judge concludes, "If I now allow the prosecution to counteract the accused's evidence by introducing proof of the other rape allegation, that proof will leave the jury's assessment of an ulterior motive about where it was before the accused introduced his door-opening evidence." The fact that the prosecution's new evidence merely cancels the accused's door-opening evidence does not mean that the prosecution's evidence lacks significant probative value. The accused has opened the door, and this has changed the baseline against which probative value of the prosecution's evidence must be measured. The appropriate question, then, is not whether the jury may perceive the probability of the material proposition - ulterior motive - as substantially different given both the challenged evidence and the door-opening evidence than it was before either item of evidence was introduced. Rather, the question is whether the jury may perceive the probability of the material proposition as 
substantially different given both items of evidence than it would if only the door-opening evidence were admitted.52

\section{B. Allocation of Responsibility}

In some cases, the proffered evidence is admissible if a predicate proposition is clearly true but inadmissible if the predicate proposition is clearly false. But if the truth of the proposition is in substantial doubt, an important procedural question arises: Should the judge exclude the proffered evidence unless she determines that the predicate proposition is true, or should she admit the evidence so long as the plausibility of the proposition might, in the view of a rational jury, exceed some (possibly undefined) threshold? The answer to this question will generally depend on whether the reason the predicate proposition appears critical is that the probative value of the proffered evidence is conditional on that proposition. Thus, the concept of conditional probative value may perform its most valuable service not so much in being applied as in being recognized, and so in assisting the allocation of responsibility between judge and jury.

Rule 104(a) provides the general rule under the classical model that - subject to Rule 104(b), the rule on conditional relevance "[p]reliminary questions" concerning the admissibility of evidence are for the trial court to decide. ${ }^{53}$ As the Supreme Court has interpreted the rule, the trial court applies a preponderance-of-theevidence standard to this decision. ${ }^{54}$

The qualification on Rule 104(a) is the rule of conditional relevance, or the somewhat more refined rule that I here term conditional probative value. If the reason a predicate proposition appears critical to the admissibility of the proffered evidence is that if the predicate proposition is assumed to be false, the proffered

52. More formally, if $A$ is the challenged evidence, $B$ is the door-opening evidence, and $X$ is the proposition that $A$ is offered to prove, it may be that Probability ( $X$ given $A, B, E$, and $O$ ) is not much different from Probability ( $X$ given $E$ and $O$ ), but that $A$ still has substantial probative value with respect to $X$, conditional on admission of $B$, because Probability ( $X$ given $A, B, E$, and $O$ ) is significantly different from Probability ( $X$ given $B, E$, and $O$ ).

A party may also open the door for herself. Suppose that in an initial evidentiary state evidence $A$ does not have sufficient probative value to warrant admissibility to prove $X$. The party then introduces evidence $B$ for the valid purpose of proving $Y$, but $B$ has the adverse consequence, from the proponent's point of view, of making $X$ appear less likely. The court may decide that, given $B, A$ has enough probative value with respect to $X$ to warrant admissibility. This would be comparable to a physician prescribing one medicine $(B)$ to address a primary symptom $(Y)$ and then prescribing another medicine $(A)$ as an antidote to a secondary symptom (impact on $X$ ) created by the first medicine.

53. FED. R. Evid. 104(a).

54. Bourjaily v. United States, 483 U.S. 171, 175-76 (1987). 
evidence has insufficient probative value to warrant admissibility, then the question is one of conditional probative value. Recall that sufficient evidence to support a finding of the predicate proposition is not essential for the proffered evidence to have enough probative value to be admissible; rather, the proffered evidence may have sufficient probative value if any of various items or groups of items of evidence is presented to the jury. If this condition is satisfied, then, assuming no other grounds for exclusion, the proffered evidence should be admitted.

A recent Supreme Court case, Huddleston v. United States, 55 provides an excellent illustration of the bearing that the concept of conditional probative value has on the threshold issue of how to resolve preliminary evidentiary questions. Huddleston was charged with, and was eventually convicted of, possessing stolen videocassettes. 56 An element of the crime ${ }^{57}$ - and, indeed, the only material issue at trial ${ }^{58}$ - was the proposition that Huddleston knew the cassettes were stolen. To help prove his knowledge, the Government offered evidence that before the cassette episode Huddleston had sold, for twenty-eight dollars apiece, thirty-eight television sets that he had obtained from the same person who provided him with the cassettes. The question before the Supreme Court was whether the trial court, before admitting this evidence, should have made a finding that the televisions were stolen. ${ }^{59}$

If it were certain that the televisions were not stolen, then, on the evidence as it stands, it is difficult to see what bearing the television episode has on the crime charged, which concerns only the cassette episode. 60 If it were certain that the televisions were stolen, then the television episode clearly has significant probative value with respect to whether Huddleston knew the cassettes were stolen. ${ }^{61}$

55. 485 U.S. 681 (1988).

56. He was also charged with selling the cassettes but was not convicted on this count. 485 U.S. at 684.

57. A federal statute makes criminally punishable "[w]hoever buys or receives or has in his possession" goods or chattels meeting the statutory terms, "knowing the same to have been embezzled or stolen." 18 U.S.C. $\$ 659$ (1988).

58. 485 U.S. at 683.

59. 485 U.S. at 682,686 .

60. Before the Supreme Court, but not before the lower courts, the Government did argue that the television evidence was relevant even if the jury could not conclude that the sets were stolen; the Court did not address this theory. 485 U.S. at 686 n.4.

61. Indeed, the Government also introduced evidence that Huddleston had made another sale of stolen appliances - refrigerators, ranges, and icemakers - that he had received from the same source. 485 U.S. at 683 . Before the Supreme Court, Huddleston did not dispute that this evidence was properly admitted. 485 U.S. at 686 n.3. 
Thus, the question whether the televisions were stolen has a clear bearing on the determination of the probative value of the evidence of Huddleston's dealings in the televisions. It therefore bears as well on the question whether the latter evidence should be excluded under Rule 402, as lacking altogether in probative value, or under Rule 403, on the ground that its probative value is substantially outweighed by the danger of prejudice and other concerns. Apart from Rules 402 and 403, however, there is no exclusionary rule that may be invoked against the evidence if the televisions were not stolen but not if they were stolen. ${ }^{62}$ Thus, except as it bears on the probative value of the evidence, the question whether the televisions were stolen has no bearing on the admissibility of Huddleston's television transactions.

Consequently, the allocation of responsibility between judge and jury becomes relatively clear, though expressing it is rather tricky. The Supreme Court expressed the allocation by holding that

Huddleston might have argued that the evidence of other episodes was not sufficiently probative, even given that the appliances were stolen, absent proof that he knew the other appliances were stolen. In other words, we might think of the condition on probative value as being a conjunction of two propositions - theft and knowledge. But in this case Huddleston was presumably aware of all the evidence of theft presented by the Government, so that evidence would probably support an inference of Huddleston's knowledge of theft - particularly viewing the three episodes together. See 485 U.S. at 691 (referring to "the low price of the televisions, the large quantity offered for sale, and petitioner's inability to produce a bill of sale," and also to Huddleston's "involvement in the sales of other stolen merchandise obtained from" the same source, including not only the refrigerators, ranges, and icemakers but also - completing the circle - the cassettes, the very merchandise involved in the charge for which he was being prosecuted).

62. At first glance, Rule 404(b) might appear to be such a rule, but it is not. That rule provides that "[e]vidence of other crimes, wrongs, or acts is not admissible to prove the character of a person in order to show action in conformity therewith," but that such evidence "may ... be admissible for other purposes, such as proof of . . knowledge . ..." FED. R. Evid. 404(b). As the Huddleston Court pointed out, this is not a general exclusion of evidence of past bad acts, with exceptions when the evidence is offered for any of various purposes. Rather, the rule "limit[s] the purpose for which [extrinsic act evidence] may be introduced." 485 U.S. at 687-88. It bars introduction of the evidence to prove character but not otherwise; to the extent the evidence is "offered for ... a proper purpose, the evidence is subject only to general strictures limiting admissibility such as Rules 402 and 403 ." 485 U.S. at 688. Even when the evidence is introduced for such a proper purpose, such as knowledge, the prohibition on introduction of the evidence for the purpose of proving character remains in effect. See 485 U.S. at 691-92 (noting that Rule 105 "provides that the trial court shail, upon request, instruct the jury that the similar acts evidence is to be considered only for the proper purpose for which it was admitted"). Thus, while proof that the televisions were stolen presumably would help the evidence of Huddleston's television dealings overcome an objection based on Rules 402 and 403 - because such proof would give the television evidence significant probative value with respect to Huddleston's knowledge that the cassettes were stolen - it would not overcome an objection under Rule 404(b). Even given such proof the narrow prohibition of that rule would apply. Indeed, ironically, absent proof that the televisions were stolen, Rule 404(b) might never come into play. The evidence simply would not support the character inference that the rule renders improper - that Huddleston, having received and sold stolen property before, was more likely than he would otherwise appear to be to have knowingly received stolen property on the occasion in question. 
the trial court should not itself "make[ ] a finding that the Government has proved the conditional fact by a preponderance of the evidence."63 Rather, that factual issue was for the jury to decide. Thus, the court itself should "simply examine [] all the evidence in the case and decide[] whether the jury could reasonably find the conditional fact - here, that the televisions were stolen - by a preponderance of the evidence."64 Many different types of evidence of theft might provide sufficient support of the predicate; in Huddleston, the low price of the televisions and the large quantity offered without a bill of sale provided ample support. 65

The argument presented in this article suggests that the Court's standard, while an accurate implementation of the classical structure provided by Rule 104(b), is still too restrictive. A better standard, avoiding the gratuitous intrusion into the fact-finding process created by the suggestion of intermediate fact-finding by the jury, would be as follows: The evidence of Huddleston's television dealings should be admitted if the evidence supporting the predicate proposition that the televisions were stolen is strong enough to give the evidence of selling enough probative value, with respect to the material issue of Huddleston's knowledge that the cassettes were stolen, to withstand an objection under Rule 403.

Even this standard might be unduly restrictive. Recall that attempts to define the predicate proposition concisely are usually doomed, because that proposition is essentially a disjunction of various evidentiary possibilities that would support the probative value of the proffered evidence. In Huddleston, for example, suppose that the televisions were not stolen but rather smuggled into the country in violation of a high tariff that, if paid, would have precluded the low price Huddleston paid for them; suppose also that no tariff barrier operated with respect to the cassettes. It remains arguable at least that the evidence of Huddleston's television dealings should be admitted; this evidence suggests strongly that Huddleston knew his source was a person willing and able to deal in goods procured at unusually low prices through illegal means, and in the absence of a tariff-avoidance explanation for the relatively low price of the cassettes, a theft explanation would be at least plausible. Therefore, it appears, the predicate evidence of smuggling - although not an act of thievery - might invest the television evidence with enough probative value to warrant admissibility.

63. 485 U.S. at 690.

64. 485 U.S. at 690.

65. 485 U.S. at 691 ; see supra note 61. 
Now the predicate is so weakened that statement of it might seem tautologous: The television evidence is inadmissible unless evidence is offered in light of which it has sufficient probative value to warrant admissibility. Yet I believe the concept of conditional probative value still does substantial good in this context. Given substantial evidence, in any of various forms, that Huddleston's source acquired the televisions improperly, the evidence of Huddleston's television dealings will probably be admissible. Given no such predicate evidence, the proffered evidence will probably be inadmissible. But the only reason that the predicate evidence has this significance is because the probative value of the proffered evidence depends on it. Given this fact, the concept of conditional probative value cautions us that it is no part of the court's job to determine whether the source did in fact acquire the televisions improperly.

\section{Implementing the Perceived Need for Intermediate Fact-} Finding

This article has argued that in determining whether to admit evidence, courts and rulemakers should avoid framing the issue in terms of whether the jury could make a given intermediate factual finding. But to the extent that courts and rulemakers continue to persist in that method, the concept of conditional probative value still plays a significant role in implementing it.

Assume, for example, that the authentication requirement remains unchanged, perhaps to effectuate the policy view that requiring evidence sufficient to support a finding of authenticity is a necessary measure to inhibit the manufacture of fraudulent evidence. The requirement then acts in effect as a rule that, if the jury is unable to conclude on the basis of admissible evidence that the proposition of authenticity is more likely true than not, then the jury must act as if that proposition is certainly untrue. If the proposition of authenticity is certainly untrue, then the proffered evidence presumably has no probative value, or at least insufficient probative value to warrant admissibility. That is, the probative value of the proffered evidence is deemed - on policy grounds, rather than as a matter of logic - to be conditional on proof sufficient to warrant a finding of the proposition of authenticity.

\section{Implementing a "Better Evidence" Rule}

Until now, I have discussed applications of the concept of conditional probative value in the near-absolute sense - that is, in terms 
of situations in which, if the predicate is satisfied, the proffered evidence has too little probative value to warrant admissibility. But recall the broader sense of conditional probative value: in some cases, the proffered evidence may have substantial probative value even absent evidence of the predicate, but substantially greater probative value if the predicate is satisfied. For example, in Blanca's hypothetical, the court might decide that the evidence of the newspaper article is quite probative of Blanca's knowledge of the material prohibition even without proof of Blanca's reading habits, but that it would be far more probative given evidence that she reads the Clarion thoroughly every day.

In such a case, the court might consider excluding the proffered evidence, not because the evidence lacks sufficient probative value to warrant admissibility, but because exclusion may induce the proponent to introduce better evidence 66 - that is, to support the proffered evidence with appropriate predicate evidence. For at least three reasons, however, the court should exercise caution before adopting such a solution.

First, in most cases - though certainly not all - it is best to allow the proponent to determine whether the incremental probative value created by introducing the predicate evidence along with the proffered evidence is worth the cost. If the sole effect of the predicate evidence is to make the proffered evidence more probative, any benefit to the truth-determining process is also a benefit to the proponent; only the proponent, however, will bear the cost of producing that evidence. The proponent's failure to produce the predicate evidence, therefore, likely reflects a decision that the incremental probative gain from producing that evidence - even if doing so would have been possible - would not be worth the cost. Only with great hesitation should the court second-guess such a judgment.

Second, excluding probative evidence in hopes of inducing the presentation of better evidence may backfire. The proponent may find that even at pain of losing the proffered evidence, producing the predicate evidence is impossible or too difficult or costly. The end result may therefore be exclusion of the proffered evidence, which by hypothesis is more probative than prejudicial.

Third, the opponent may be in substantially as good a position as the proponent to produce the predicate evidence. If the predi-

66. I follow a suggestion by Professor Tillers to use the term better evidence rather than the more common, but less universally accurate, term best evidence. 
cate evidence has some effect other than to make the proffered evidence more probative, the opponent may also find it worthwhile to produce the predicate evidence. Thus, the court might find it best to admit the proffered evidence without insisting on production of the predicate evidence, leaving it to the opponent to produce that evidence if she finds doing so worthwhile. 67

Notwithstanding all these cautions, I believe there are limited situations in which the court should at least tentatively exclude the proffered evidence because that evidence would be so much better in association with the predicate evidence. The court might do so, for example, if it concludes that the predicate evidence could be easily produced by the proponent but not - at least unless the proponent provided essential information - by the opponent, who also has no incentive to produce it; that the proponent is litigating lazily and needs a spur to produce the predicate evidence; and that the proffered evidence is too crucial to the proponent for him to do without it. In Part V, I present a proposed rule implementing "better evidence" principles in the context of authentication. I will not attempt here, however, to formulate a comprehensive rule prescribing when evidence should be excluded on the ground that the evidence offered together with predicate evidence would have substantially greater probative value and so be "better evidence." This issue is tied to the general question of the appropriate nature of "better evidence" rules, and that in turn is a broad issue beyond the scope of this article. ${ }^{68}$

\section{Proposed Rules Revisions}

I will attempt to crystallize much of the above discussion by offering proposed revisions to several of the Federal Rules of Evidence, along with some explanatory commentary.

67. Dale Nance, in the general context of "best evidence" problems, points out potential problems in relying on the opponent's incentive to produce countervailing evidence. Dale A. Nance, The Best Evidence Principle, 73 IowA L. REv. 223, 263-70 (1988). I agree that in some circumstances such reliance is misplaced, but I do not believe the potential problems should lead to a presumptive rule against such reliance. Nor do I believe that when the proponent fails to offer the best evidence possible, these problems should generally cause a court to readily embrace exclusions as a remedy even though the offered evidence is useful.

68. The most commonly recognized "better evidence" rule, usually known as the "best evidence rule," is the body of doctrine favoring the production of documentary originals. See FED. R. EvID. 1001-1008. In the situation covered by that doctrine, the "better" evidence is not the proffered evidence accompanied by another piece of evidence but rather an alternative form of evidence, generally the documentary original or its equivalent. Furthermore, the "better evidence" favored by that doctrine is deemed better not so much because it is more probative as because it is less likely to be fabricated - and therefore less likely to have unjustified persuasive power. 


\section{A. Rule 104(b)}

Most important, for purposes of this article, is Rule 104(b), the basic conditional relevance rule. I propose revising it to read as follows:

(b) Probative value conditional on further evidence. When a proffered item of evidence has insufficient probative value to warrant admissibility on the current state of the evidence but would have sufficient probative value to warrant admissibility on some other evidentiary states, the court may in its discretion admit the evidence subject to the introduction of evidence to achieve such another evidentiary state.

Note that this formulation avoids the problems of current Rule 104(b). It speaks in terms of probative value rather than of relevance. It does not intrude into the jury's function by speaking of a gratuitous intermediate finding of fact, and it avoids the complexities and possible confusion created by speaking of a predicate proposition. Instead it refers to a simple conditionality - the proffered evidence's having significant probative value on some other evidentiary states but not on the current one. If there is one such other evidentiary state, there will be an infinite number, even if they vary in only small degrees. To invoke this rule, the court need not specify what a qualifying evidentiary state would be, though of course ordinarily it should give some guidance.

The current rule says that if the predicate is satisfied the court "shall" admit the evidence. My proposal contains no such provision, for two reasons. First, such a provision is misleading. It is not true that if the predicate for relevance or significant probative value of the evidence is satisfied, the evidence should always be admitted; the evidence may carry an intolerable amount of prejudicial baggage, or there may be other grounds for exclusion. Second, if the provision is meant to accommodate these considerations, it is extraneous; given that the predicate is satisfied, the court's role is simply to determine, in its discretion and in accordance with the other rules of evidence, whether the probative value of the evidence outweighs its prejudicial potential and whether other factors require exclusion.

The proposed rule speaks of the introduction of further evidence in neutral terms, because such a state might be achieved either by the proponent offering linking evidence or the opponent offering door-opening evidence. Also, the proposed rule addresses only the situation in which the concept of conditional probative value may be brought into play in an operationally significant way 
- when the court decides that the evidence does not currently have sufficient probative value to warrant admissibility but nevertheless admits it in anticipation that the evidentiary state will change sufficiently to make admission prudent. The proposed rule does not address purely analytical uses of the concept of conditional probative value, as in the analysis of the premises on which the evidence has significant probative value; for those uses, no rule is necessary.

\section{B. Rule 104(a)}

Closely associated with Rule 104(b) is Rule 104(a). The following is a proposed amendment to that rule, with italics to indicate language to be added and brackets to indicate language to be deleted:

(a) Questions of admissibility generally. Preliminary questions concerning the qualification of a person to be a witness, the existence of a privilege, or the admissibility of evidence shall be determined by the court[, subject to the provisions of subdivision (b)]. In making its determination it is not bound by the rules of evidence except those with respect to privilege. That the probative value of proffered evidence is conditional on the truth of a given proposition is not a ground on which the truth or falsity of that proposition shall be deemed a preliminary question within the meaning of this rule.

The principal idea behind this proposed change is that because Rule 104(b) should not call on the jury to make factual findings on "preliminary questions," Rule 104(b) is not a qualification of Rule 104(a) but a provision of a substantially different type. The additional sentence is meant to accentuate this point. In a case like Huddleston, the judge might reason as follows:

Obviously, the evidence of Huddleston's dealing in televisions has greater probative value if the televisions were stolen, but that fact does not make the question whether the televisions were stolen a preliminary question for my determination. What I have to determine is whether, given all the evidence in the case and all the knowledge the jurors may validly bring from outside, the evidence of Huddleston's dealings has enough probative value to warrant admissibility and whether there is any other consideration requiring exclusion.

\section{Rule 602}

The requirement that a witness have personal knowledge of the subject matter of her testimony is in part a specialized application of the concept of conditional probative value: if the witness merely concocted her testimony, it has little or no probative value. This concern does not express the full extent of the rule, however, for in 
some cases testimony may have substantial probative value although the witness lacks personal knowledge of the subject matter. ${ }^{69}$ In part, then, the personal knowledge requirement is a device for the enforcement of other exclusionary rules; if it turns out that the witness is basing her testimony on information that she would not be allowed to testify to, such as hearsay not within any exemption, then presumably the court should not allow the inference to be admitted either. ${ }^{70}$ In part the requirement is also a reflection of the "better evidence" principle; if the basis for the testimony is information that the witness is capable of transmitting in a way comprehensible to the fact finder, and if the testimony of that information would otherwise be valid, then such information-loaded testimony is presumably preferable to the mere report of the witness's inference. ${ }^{71}$

The requirement is thus very complicated, and I will not attempt here to devise a formulation expressing all its various parts. ${ }^{72}$ Here, though, is a modest-seeming revision of Federal Rule of Evidence 602:

A [witness may not testify to a matter unless evidence is introduced sufficient to support a finding] witness' testimony concerning $a$ matter shall be deemed to have probative value only to the extent that the witness has personal knowledge of the matter. Evidence to prove personal knowledge may, but need not, consist of the witness' own

69. See Nance, supra note 9 , at 489 . It may be, for example, that the witness is relying on rumor or other hearsay for her conclusion. Rumor may be unreliable, but at least in some circumstances the witness is more likely to have heard a rumor of a given proposition if the proposition was true than if it was false; in such a case, the witness's testimony would have probative value. Also, the witness, although lacking personal knowledge of the factual proposition to which she has testified, may have inferred the truth of that proposition from information that she did have. An example would be a lay witness who testifies as to which party was at fault in an auto accident that she did not see, but the cause of which she believes she knows from having observed the position of the cars after the accident. To the extent feasible, our system generally prefers that she testify to what she knows from her own personal knowledge and that she leave the process of inference to the fact finder. But this does not mean that her testimony lacks probative value.

70. Admissions by or attributable to a party opponent are traditionally relieved from the personal knowledge requirement, however.

71. This aspect of the requirement usually should not apply to hearsay declarants; exclusion of the hearsay statement will not induce the making of a better, more explanatory statement.

In part, too, the requirement is probably meant to establish a certain order of questioning; before a witness is allowed to state an inference, the proponent should attempt to establish what her basis for the inference is. Similarly, the proponent of a hearsay declaration should attempt to establish the basis for any inference drawn by the declarant.

72. Dale Nance is making valiante efforts - not yet to his complete satisfaction - in that direction. See Letter from Professor Dale A. Nance, Chicago-Kent College of Law, to Richard D. Friedman, University of Michigan Law School 3-4 (Sept. 7, 1994) (on file with author). 
testimony. This rule is subject to the provisions of Rule 703, relating to opinion testimony by expert witnesses.

This rendition of the rule is rather unusual and requires explanation.

Suppose that a witness is prepared to testify that she observed the incident in dispute and to describe it. If the court believes that the witness did not actually perceive the incident and that she merely concocted her testimony or drew inferences from other information that she did receive, whether firsthand or not, it could not appropriately exclude the testimony from the jury's consideration on that ground alone. It is for the jury to determine whether the witness observed the incident.

For the reasons described in this article, the jury might reasonably give the testimony weight even if it is inclined to believe that the witness is more likely than not lying about having observed the incident. Hence, my proposed revision eliminates the artificial intermediate fact-finding that is central to the current rule. But if the jury does have doubt about whether the witness observed the incident, the proposed rule tells the jury to discount the probative value it attributes to the testimony to reflect that doubt - hence the "deemed" language. If the basis for the jury's doubt is merely its belief that the witness may have concocted the story, no instruction is necessary to achieve this result. But to the extent that the jury believes that the witness based the testimony on information that she received, whether firsthand or not, the instruction is necessary. It effectively operates as an imposition on the jury's fact-finding process-an intrusion on that process, to be sure, but one meant to enlist the jury's aid in implementing a policy preference for factreporting, firsthand testimony.

Of course, the court too has a role in implementing that preference. If a rational jury would have doubts about the witness's personal knowledge, the proposed rule indicates that this should lessen the chance that the evidence should be held admissible. Indeed, if it is clear that the witness has no personal knowledge of the subject matter, then no probative value can be attributed to the testimony, and it is inadmissible.

\section{Rule 901(a)}

Authentication is another specialized application of the concept of conditional probative value. In accordance with the analysis of this article, I believe the general requirement of authentication should be eliminated and replaced by a less demanding application 
of "better evidence" principles. Therefore, I propose amending Rule 901(a), the general provision stating the basic authentication requirement, as follows:

(a) General Provision. [The] There shall be no separate requirement of authentication or identification as a condition precedent to admissibility [is satisfied by evidence sufficient to support a finding that the matter in question] unless there is substantial doubt that the proffered evidence is what its proponent claims and the proponent of the evidence is substantially better able than the opponent to produce evidence bearing on that question.

Note that this proposal, like the others, does not depend on intermediate factual findings. Authenticating evidence is necessary under this proposal only when each of two conditions holds true substantial doubt about the authenticity of the proffered evidence, and a substantial comparative advantage on the proponent to produce evidence bearing on authenticity. It logically follows that when the proponent has produced such evidence that either of these conditions no longer holds true, the requirement is satisfied. Indeed, if the proponent's only comparative advantage in presenting the predicate evidence is that the proponent knows the nature, identity, and location of such evidence, the proponent can eliminate that advantage - and thereby satisfy the requirement - without presenting any authenticating evidence at all, simply by providing that information to the opponent.

\section{CONCLUSION}

The critics are certainly correct that the classical concept of conditional relevance is overstated and overly rigid. But there is significant value in the more flexible concept I have called conditional probative value. Understanding this concept helps in the analysis of basic probative value problems and provides the underpinnings for "linking up" and "door opening" decisions. It helps provide the framework for understanding the allocation of fact-finding responsibility between judge and jury. Finally, it tolerates a somewhat more liberal attitude toward the personal knowledge requirement and a significantly more liberal and practical attitude towards the authentication requirement than does present law. 